\title{
Novel Thermoplastic Polyhydroxyurethane Elastomers as Effective Damping Materials over Broad Temperature Ranges
}

\author{
Goliath Beniah ${ }^{1}$, Kun Liu ${ }^{2}$, William H. Heath ${ }^{3}$, Matthew D. Miller ${ }^{3}$, \\ Karl A. Scheidt ${ }^{2}$, John M. Torkelson ${ }^{1,4 *}$
}

${ }^{1}$ Dept. of Chemical and Biological Engineering, Northwestern University, Evanston IL, 60208 USA

${ }^{2}$ Dept. of Chemistry, Northwestern University, Evanston, IL 60208 USA

${ }^{3}$ The Dow Chemical Company, Freeport, TX 77541 USA

${ }^{4}$ Dept. of Materials Science and Engineering, Northwestern University, Evanston, IL 60208 USA

*Correspondence to: Prof. John M. Torkelson (Email: j-torkelson@northwestern.edu)

\begin{abstract}
Non-isocyanate thermoplastic polyhydroxyurethane (PHU) elastomers were synthesized from cyclic carbonate aminolysis using polytetramethylene oxide (PTMO) as soft segment and divinylbenzene dicyclocarbonate and three diamine chain extenders as hard segment with a range of hard-segment content. Characterization was done via Fourier transform infrared spectroscopy, small-angle X-ray scattering (SAXS), uniaxial tensile testing, and dynamic mechanical analysis (DMA). SAXS reveals that these PHUs possess nanophaseseparated morphology with $10-20 \mathrm{~nm}$ interdomain spacings. These PHUs display elastomeric response and tunable tensile properties with Young's modulus ranging from 27 to $200 \mathrm{MPa}$, tensile strength from 0.3 to $9.7 \mathrm{MPa}$ and elongation at break ranging up to greater than $2000 \%$. DMA reveals that nanophase separation in these PHUs is accompanied by broad interphases having a wide range of local composition; this nanophase separation differs significantly from that manifested by thermoplastic polyurethane elastomer (TPU) due to hydrogen bonding of hydroxyl groups in the hard segments to the PTMO soft segment. These PHUs show very good damping performance with $\tan \delta \geq 0.30$ over broad temperature ranges $\left(\geq 60{ }^{\circ} \mathrm{C}\right)$, which are tunable through simple variation of hard-segment content and chain extender structures.
\end{abstract}


Keywords: Non-isocyanate; polyurethane; polyhydroxyurethane; damping material.

\section{INTRODUCTION}

Polyurethane is one of the most important commodity polymers in the world with an estimated world-wide production of 18 million tons in 2016 [1]. It is used in a wide range of applications, including flexible and rigid foams, coatings, adhesives, elastomers and biomedical implants [1-4]. It is produced from a step growth reaction between isocyanate and alcohol with relatively fast reaction kinetics. Despite its wide-ranging applications, in recent years there have been increasing constraints on the use, transport and handling of isocyanate from various regulatory bodies such as the United States Environmental Protection Agency and the European Union [5-7]. These constraints have fueled significant efforts from both academic and industrial research communities to develop alternatives to PU materials that are synthesized without employing isocyanate-based chemistry.

Cyclic carbonate aminolysis has emerged as one of the most promising chemistries to produce PU-like material without using isocyanate [8-12]. This chemistry relies on the ring opening of five-, six-, seven-, or eight-membered-ring cyclic carbonates by amine moieties to produce polyhydroxyurethane (PHU) that is analogous to PU with the exception of an additional primary or secondary hydroxyl group adjacent to the urethane linkage [2,8-12]. Five-memberedring cyclic carbonates can be easily obtained from a carbon dioxide insertion reaction into an epoxy ring enabling the generation of carbonate monomers from various epoxy precursors [13]. In recent years, numerous studies have investigated PHU synthesis with strong emphasis on the production of single-phase PHUs, crosslinked PHU networks, reaction catalysis and the synthesis of carbonate monomers [12-51]. For example, Endo and coworkers [13-22], as well as others [23-28], synthesized PHUs from carbonated epoxy resins (such as Bisphenol A diglycidyl ether, hydroquinone diglycidyl ether, and butanediol diglycidyl ether) and small-molecule diamines (such as hexamethylene diamine) resulting in single-phase PHUs [13-28]. The reaction

kinetics of five-, six- [17,18, 51], seven- [19] and eight-membered ring carbonates [12], the 
influence of substituent on reactivity [20,52], and the effects of catalysts [21,29-31] were also characterized. Renewable resources such as carbonated soybean oil, linseed oil [32-35], limonene [36], cellulose [37], isosorbide [38], cashew nut shell liquid [40], and glycerol [41] have been used to make crosslinked PHUs [32-43]. Other investigators have studied various routes to generate cyclic carbonate monomers for synthesizing single-phase and crosslinked PHUs [44-49] as well as the increased reactivity of eight-membered ring carbonates allowing room temperature synthesis without the aid of catalysts [12].

While extensive research has been done on PHU synthesis, relatively little work has focused on nanophase-separated PHUs as thermoplastic elastomer [53,54]. Only one study has contributed to understanding the role of hydroxyl groups in modifying the properties of thermoplastic PHU elastomer in comparison to analogous, isocyanate-based thermoplastic PU elastomers (TPUs) [54]. TPUs are obtained from step-growth reactions between long-chain diol as the soft segment and diisocyanate with chain extender as the hard segment. The soft segment has a glass transition temperature $\left(T_{\mathrm{g}}\right)$ below room temperature whereas the hard segment has a $T_{\mathrm{g}}$, or in some cases a melt temperature $\left(T_{\mathrm{m}}\right)$, above room temperature. The incompatibility between the two segments and the hydrogen bonding between polar urethane units result in nanophase separation in TPU; the hard domains dispersed in a rubbery matrix act as physical crosslinking sites, leading to elastomeric character [55,56].

TPUs typically exhibit very good nanophase separation with narrow $T_{\mathrm{g}}$ ranges of their respective components [57-69]. Dynamic mechanical analysis (DMA) of TPUs typically shows sharp transitions with well-defined loss tangent $(\tan \delta)$ peaks over a narrow temperature range [57-69]. A common criterion to identify effective, broad-temperature-range, acoustic and/or vibration damping materials is $\tan \delta \geq 0.30$ over at least a $60{ }^{\circ} \mathrm{C}$ temperature range [70-78]. Given its characteristic viscoelastic response, TPU by itself cannot serve as a broad-temperaturerange acoustic damping material. To increase the $T_{\mathrm{g}}$ breadth, efforts have been made to combine TPUs with secondary polymeric components such as epoxy [74], polyester [75], polyacrylate [76,77], polystyrene [78], etc. into crosslinked interpenetrating polymeric network (IPN) 
structures. The intimate mixing created by an IPN structure produces microheterogenous domains with a range of local compositions and a broad tan $\delta$ profile [70-78].

Recently, Torkelson and coworkers [54] reported the synthesis and characterization of thermoplastic PHU elastomer from several polyether-based soft segments. They compared PU and PHU having analogous chemical structures and demonstrated that the hydroxyl groups in PHU play a critical role in the development of nanophase separation in segmented PHUs. When a polyethylene oxide (PEO)-based soft segment is used, significant phase mixing occurs due to the high density of oxygen atoms in PEO resulting in PHU that flows under the force of gravity; in contrast, an analogous TPU synthesized from PEO-based soft segment shows good mechanical properties [54,57]. This difference is due to hydrogen bonding of hard-segment hydroxyl groups in PHU to oxygen atoms in PEO soft segments. This hydrogen bonding can be suppressed by using polypropylene oxide (PPO)-based soft segments with sterically hindered oxygen atoms and polytetramethylene oxide (PTMO)-based soft segments with dilution of oxygen atom content relative to PEO-based soft segments. In a limited demonstration, Torkelson and coworkers [54] showed that the hydroxyl groups can be advantageous in PTMO-based PHUs yielding good damping properties over a broad temperature range, a function not observed in isocyanate-based TPUs [57-69]. The presence of some level of phase mixing results in materials with broad interphases having a wide range of local composition and therefore broad $T_{\mathrm{g}}$ responses. As viscoelastic polymeric materials possess the most effective damping properties near their $T_{\mathrm{g}} \mathrm{s}$, such responses allow PTMO-based PHUs to serve as acoustic damping materials over a broad range of use temperature without the need to produce IPN structures.

Here, we describe a more complete study of PTMO-based segmented, thermoplastic PHUs as damping materials over broad and tunable temperature ranges without employing IPN structures. The tunability of temperature range for good damping performance can be achieved through variation in hard-segment content and chain-extender structure. We synthesized and characterized a series of PHUs with three different chain extenders at four different hardsegment contents. Small-angle X-ray scattering (SAXS) demonstrates the presence of 
nanophase-separated morphology within these materials. Tensile tests demonstrates elastomericlike material responses with tunable mechanical properties. DMA demonstrates that these materials exhibit high $\tan \delta$ values $(\geq 0.30)$ over broad and tunable temperature ranges of at least $60{ }^{\circ} \mathrm{C}$. The thermoplastic nature of these broad-temperature-range, PHU damping materials allow them to be molded and shaped into various forms to suit multiple needs.

\section{EXPERIMENTAL}

Materials. Diamine-terminated PTMO (XTJ-548, $\left.M_{\mathrm{n}}=1700 \mathrm{~g} / \mathrm{mol}\right)$ was supplied by Huntsman Corporation. Hydroxyl-terminated PTMO $\left(M_{\mathrm{n}}=2000 \mathrm{~g} / \mathrm{mol}\right), 2$,4-tolylene diisocyanate $(2,4-$ TDI, 95\%), 1,4-cyclohexanedimethanol (mixture of cis and trans isomers, 99\%), 1,6-hexanediol (99\%), dibutyltindilaurate (DBTDL), 1,4-butanediol (BDO, 99\%), 1,3-cyclohexanebis(methyl amine) (CYCDA, mixture of isomers, 99\%) and hexamethylene diamine (HMDA, 98\%) were purchased from SigmaAldrich and used as received. p-xylylene diamine (pXDA, 99\%) was purchased from TCI America and used as received. Dimethylformamide (DMF) was purchased from Fischer Scientific and used as received. Divinylbenzene dicyclocarbonate (DVBDCC) was synthesized according to the procedure outlined in ref. 54 .

Synthesis of Thermoplastic PHU Elastomer. All PHUs were synthesized following Scheme 1. Material formulations were varied by adjusting molar ratios of reacting components according to Table 1. The hard-segment content is defined by (weight of DVBDCC + weight of chain extender)/(weight of DVBDCC + weight of chain extender + weight of XTJ-548). The naming convention for PHUs in this study is CYCDA-XX, HMDA-XX, and pXDA-XX for PHUs chain extended with 1,3-cyclohexanebis(methyl amine), hexamethylene diamine and p-xylylene diamine, respectively, whereas $\mathrm{XX}$ indicates the hard-segment content in the material. For example, CYCDA-40 is synthesized with 1,3-cyclohexanebis(methyl amine) as the chain extender with $40 \mathrm{wt} \%$ hard-segment content. In a typical synthesis of CYCDA-40, $2 \mathrm{~g}(8 \mathrm{mmol})$ of DVBDCC, $4.152 \mathrm{~g}(2.59 \mathrm{mmol})$ of XTJ-548 and $0.77 \mathrm{~g}(5.41 \mathrm{mmol})$ of $1,3-$ cyclohexanebis(methyl amine) were combined in a FlackTek max 20 cup. Then, $6.3 \mathrm{~mL}$ of DMF 
were added to adjust the concentration of reacting functional groups to $0.60 \mathrm{M}$. The mixture was then homogenized in a FlackTek SpeedMixer ${ }^{\mathrm{TM}}$ for $5 \mathrm{~min}$ at $3500 \mathrm{rpm}$. Then, it was reacted at $70{ }^{\circ} \mathrm{C}$ for $24 \mathrm{hr}$. Upon completion of reaction, the mixture was homogenized again for $5 \mathrm{~min}$. The mixture was poured into a FlackTek max 50 cup and dried in an oven maintained at $70{ }^{\circ} \mathrm{C}$ for at least $24 \mathrm{hr}$ to remove solvent. The dried materials were hot-pressed into a 1-mm-thick sheet at $\sim 100{ }^{\circ} \mathrm{C}$ using a PHI (Model 0230C-X1) press with 5 ton ram force.

Table 1 Composition, thermal properties as determined from dynamic mechanical analysis, interdomain spacings determined from SAXS and temperature range with good damping performance of PTMO-based PHUs. HS: hard segment, CE: chain extender, SS: soft segment.

\begin{tabular}{c|c|c|c|c|c|c|c}
\hline Sample Name & $\begin{array}{c}\text { Molar Ratio } \\
(\mathrm{HS} / \mathrm{CE} / \mathrm{SS})\end{array}$ & $\begin{array}{c}\text { HS Content } \\
(\mathrm{wt} \%)\end{array}$ & $\begin{array}{c}d \text {-spacing } \\
(\mathrm{nm})\end{array}$ & $\begin{array}{c}\mathrm{SS} T_{\mathrm{g}} \\
\left.\left({ }^{\circ} \mathrm{C}\right)\right)^{\mathrm{b}}\end{array}$ & $\begin{array}{c}T_{\text {flow }} \\
\left({ }^{\circ} \mathrm{C}\right)^{\mathrm{c}}\end{array}$ & $\begin{array}{c}T(\tan \delta \geq \\
0.30)\left({ }^{\circ} \mathrm{C}\right)\end{array}$ & $\begin{array}{c}\Delta T \\
\left({ }^{\circ} \mathrm{C}\right)\end{array}$ \\
\hline CYCDA-30 & $2.1 / 1.1 / 1$ & 30 & 11.7 & -61 & 51 & $-27-51$ & 78 \\
CYCDA-40 & $3.1 / 2.1 / 1$ & 40 & 12.7 & -66 & 80 & $-1-80$ & 81 \\
CYCDA-50 & $4.4 / 3.4 / 1$ & 50 & 13.3 & -66 & 89 & $32-89$ & 57 \\
CYCDA-60 & $6.5 / 5.5 / 1$ & 60 & 16.4 & -67 & 92 & $38-92$ & 54 \\
\hline HMDA-30 & $2.2 / 1.2 / 1$ & 30 & 14.7 & -63 & 40 & $-33-40$ & 73 \\
HMDA-40 & $3.2 / 2.2 / 1$ & 40 & 15.0 & -65 & 48 & $-9-48$ & 57 \\
HMDA-50 & $4.7 / 3.7 / 1$ & 50 & 15.2 & -66 & 54 & $10-54$ & 44 \\
HMDA-60 & $6.9 / 5.9 / 1$ & 60 & 16.4 & -65 & 64 & $16-64$ & 48 \\
\hline pXDA-30 & $2.1 / 1.1 / 1$ & 30 & 12.4 & -62 & 50 & $-31-50$ & 81 \\
pXDA-40 & $3.1 / 2.1 / 1$ & 40 & 14.6 & -66 & 75 & $0-75$ & 75 \\
pXDA-50 & $4.5 / 3.5 / 1$ & 50 & 14.6 & -63 & 80 & $10-80$ & 70 \\
pXDA-60 & $6.6 / 5.6 / 1$ & 60 & 17.2 & -66 & 90 & $26-90$ & 64 \\
\hline
\end{tabular}

${ }^{a}$ Interdomain spacing is calculated using $\mathrm{d}=2 \pi / q_{\max }$.

${ }^{\mathrm{b}}$ Determined from the peak in the loss modulus $\left(E^{\prime \prime}\right)$ curves in DMA on heating from $-100{ }^{\circ} \mathrm{C}$ to $150{ }^{\circ} \mathrm{C}$ at a rate of $3{ }^{\circ} \mathrm{C} / \mathrm{min}$, frequency of $1 \mathrm{~Hz}$, and strain of $0.03 \%$.

${ }^{\mathrm{c}} T_{\text {flow }}$ is defined as the temperature at which the material starts to irreversibly deform; this is often reported as the temperature prior to inconsistent $\tan \delta$ data, close to the temperature at which the sample is no longer mechanically robust.

Synthesis of Thermoplastic PU Elastomer. The analogous TPUs used in this study were synthesized with hydroxyl-terminated PTMO, 2,4-TDI, 1,4-cyclohexanedimethanol and 1,6hexanediol at $30 \mathrm{wt} \%$ hard-segment content. The hydroxyl-terminated PTMO was first dried by bubbling through nitrogen at $130{ }^{\circ} \mathrm{C}$ overnight prior to use. In a typical synthesis of TPU chain extended with 1,6-hexanediol, $10 \mathrm{~g}(5 \mathrm{mmol})$ of PTMO were reacted with $2.91 \mathrm{~g}(16.7 \mathrm{mmol})$ of 2,4-TDI in a three-necked flask equipped with overhead stirrer at $60{ }^{\circ} \mathrm{C}$ for $2 \mathrm{hr}$ with $10 \mu \mathrm{L}$ of DBTDL as catalyst. The resulting prepolymer was transferred into a mixing cup, and $1.38 \mathrm{~g}$ (11.7 mmol) of 1,6-hexanediol were added and mixed for $30 \mathrm{~s}$ at $3500 \mathrm{rpm}$ in a FlackTek mixer. The mixture was poured into a mold and cured at $60{ }^{\circ} \mathrm{C}$ for $2 \mathrm{hr}$. A similar procedure was used to 
synthesize PU chain extended with 1,4-cyclohexanedimethanol at $30 \mathrm{wt} \%$ hard-segment content.

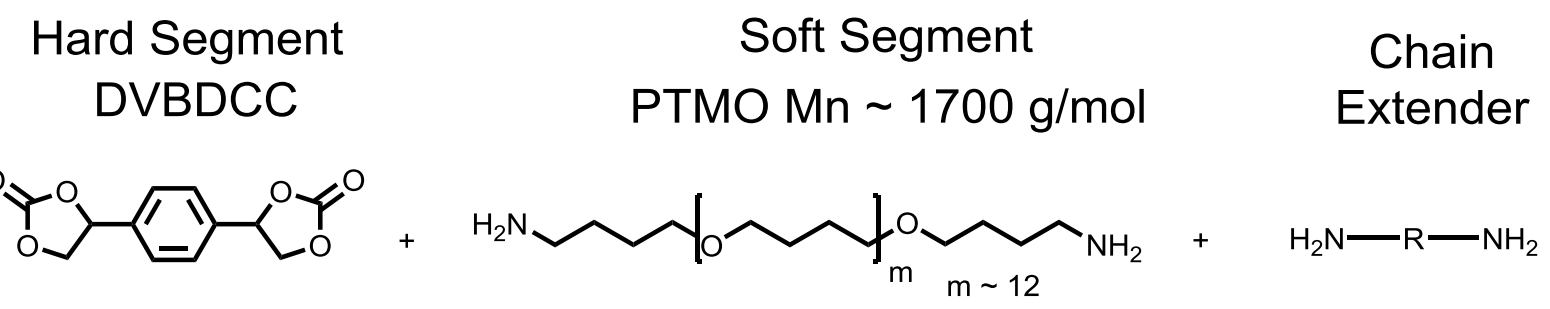<smiles>O=C1OCC(c2cccc(C3COC(=O)O3)c2)O1</smiles>

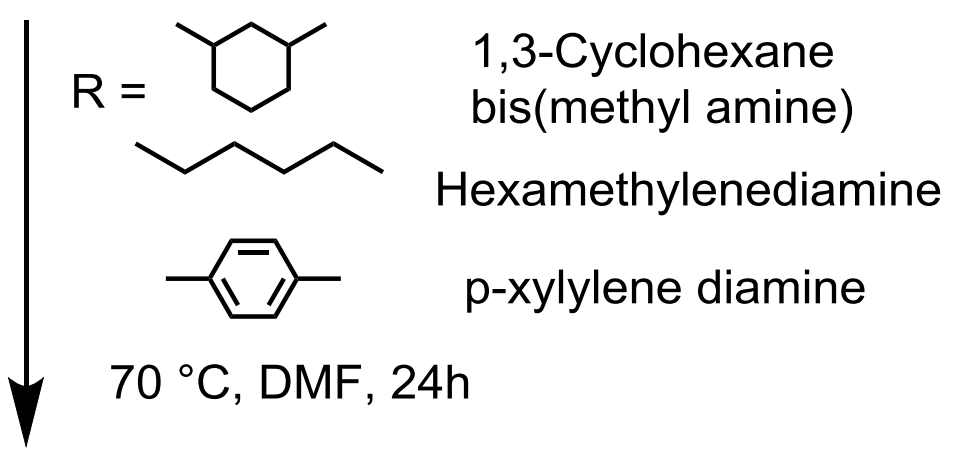<smiles>CCC(=O)OC(CO)c1ccc(C(O)COC(=O)NCCCCOC(C)(C)CCCCOCCCCNC(=O)OC(CO)c2cccc(C(O)COC(=O)NPNC(C)C)c2)cc1</smiles>

Scheme 1 Reaction scheme for the formation of segmented PHUs from DVBDCC, PTMO and chain extenders. The PHUs can either possess a $1^{\circ}$ or $2^{\circ}$ hydroxyl group; a mixture of these products is expected.

Attenuated Total Reflectance-Fourier Transform Infrared (ATR-FTIR) Spectroscopy. All

PHUs were analyzed for complete conversion of carbonate groups with a Bruker Tensor $37 \mathrm{Mid}$ IR FTIR spectrometer equipped with an ATR diamond/ZnSe attachment. Dried materials were scanned at a resolution of $4 \mathrm{~cm}^{-1} ; 32$ scans were obtained in the $4000-600 \mathrm{~cm}^{-1}$ range for each spectrum.

${ }^{1}$ H NMR Spectroscopy. ${ }^{1} \mathrm{H}$ NMR spectra were recorded on a Bruker Avance III $500 \mathrm{MHz}$ NMR spectrometer with a direct cryoprobe at room temperature in deuterated chloroform $\left(\mathrm{CDCl}_{3}\right)$. Spectra are reported in parts per million relative to tetramethylsilane.

Molecular Weight Characterization. The molecular weights (MWs) of PHUs were determined using gel permeation chromatography. A Waters 2695 separation module and two Tosoh TSKgel Alpha-M columns $(13 \mu \mathrm{m})$ in series were used. The eluent was DMF with $4 \mathrm{~g} / \mathrm{L}$ of $\mathrm{LiNO}_{3}$ at 40 
${ }^{\circ} \mathrm{C}$; the elution rate was $0.5 \mathrm{~mL} / \mathrm{min}$. The detector was a Viscotek TDA 302 interface/Waters 2414 RI detector. Molecular weight values were reported relative to polyethylene oxide (PEO) standards. Agilent PEO/PEG EasiCal standards were used for calibration.

Small-Angle X-Ray Scattering. SAXS experiments were performed using a Rigaku S-MAX 3000 SAXS system emitting X-rays with a wavelength of $0.154 \mathrm{~nm}(\mathrm{Cu}-\mathrm{K} \alpha)$. The sample-todetector distance was $1640 \mathrm{~mm}$ with silver behenate calibration. The 2D scattering patterns were azimuthally averaged to produce 1-D plots of intensity versus scattering vector $q$, where $q=$ $4 \pi \sin \theta / \lambda ; \theta$ is one-half of the scattering angle, and $\lambda$ is the $\mathrm{X}$-ray wavelength.

Tensile Testing. Tensile properties were obtained according to ASTM D1708 standard with an MTS Sintech 20/G tensile tester. Dog bone-shaped samples (4.7 mm x $1.0 \mathrm{~mm}$ x $22 \mathrm{~mm}$ ) were cut using a Dewes-Gumbs die from dried sheets and subjected to an extension rate of 130 $\mathrm{mm} / \mathrm{min}$. Tensile tests were performed approximately 2-3 days after the samples were compression molded. The Young's modulus, tensile strength and elongation at break were reported as average values of five specimens. The Young's Modulus values were determined from the initial slope of the stress-strain curves in the linear region.

Differential Scanning Calorimetry (DSC). DSC experiments were performed with a Mettler Toledo DSC 822e. Samples were tested from 30 to $250{ }^{\circ} \mathrm{C}$ at a heating rate of $10^{\circ} \mathrm{C} / \mathrm{min}$.

Dynamic Mechanical Analysis. DMA experiments were performed with a TA Instruments Rheometrics Stress Analyzer-GIII. Rectangular specimens measuring $8 \mathrm{~mm}$ in width and $0.9 \mathrm{~mm}$ in thickness were cooled with $\mathrm{N}_{2}$ gas to $-100{ }^{\circ} \mathrm{C}$ and subjected to a temperature sweep from -100 ${ }^{\circ} \mathrm{C}$ to $120{ }^{\circ} \mathrm{C}$ at a heating rate of $3{ }^{\circ} \mathrm{C} / \mathrm{min}$. The measurements were conducted in tensile mode with frequency of $1 \mathrm{~Hz}$ and strain of $0.03 \%$. The storage modulus $\left(E^{\prime}\right)$, loss modulus ( $\left.E^{\prime \prime}\right)$ and loss tangent $(\tan \delta)$ were recorded. The soft-segment $T_{\mathrm{g}}$ was identified from the peak maximum in $E$ "; the flow temperature was defined as the onset of inconsistent tan $\delta$ data, close to the temperature at which the sample was no longer mechanically robust.

\section{RESULTS AND DISCUSSION}




\section{Synthesis and Characterization}

All PHUs were synthesized according to Scheme 1. Table 1 lists the formulation of starting materials. Three chain-extender molecules were used, and four hard-segment contents for each chain extender structure were studied. The hard-segment contents were varied by adjusting the molar ratios of DVBDCC hard segment and chain extender relative to that of PTMO soft segment. The progress of synthesis was monitored using ATR-FTIR spectroscopy via the disappearance of the carbonyl stretching band at $\sim 1800 \mathrm{~cm}^{-1}$ originating from DVBDCC. Figure S1a-c reports typical FTIR spectra of all PHUs along with the spectrum of DVBDCC. The peak associated with the carbonate group disappeared in the final materials indicating a complete conversion of carbonate functional groups into hydroxyurethane linkages within experimental error. The appearance of urethane peaks at $1730-1700 \mathrm{~cm}^{-1}$ confirms successful PHU formation. These peaks represent contributions from free, non-hydrogen bonded ( 1730 $\left.\mathrm{cm}^{-1}\right)$ and hydrogen bonded $\left(\sim 1700 \mathrm{~cm}^{-1}\right)$ urethane units. In addition, peaks associated with $\mathrm{N}-\mathrm{H}$, $\mathrm{O}-\mathrm{H}, \mathrm{C}-\mathrm{O}, \mathrm{C}=\mathrm{C}$, and $\mathrm{C}-\mathrm{H}$ bonds from various segments in the polymer chain were also present. The chemical structures of the resulting polymers were also analyzed using ${ }^{1} \mathrm{H}$ NMR spectroscopy. Figures S2-S4 show typical spectra of (three of the twelve) PHUs produced in this study: CYCDA-40, HMDA-40, and pXDA-40, respectively. Signals from various protons along the polymer chain were identified and assigned accordingly as indicated.

The apparent MWs of these PHUs were characterized using GPC and are reported in Table S1. The apparent $M_{\mathrm{n}}$ values of these PHUs range from 3.1 to $10.0 \mathrm{~kg} / \mathrm{mol}$ whereas the apparent $M_{\mathrm{w}}$ values range from 12.2 to $48.3 \mathrm{~kg} / \mathrm{mol}$. The challenge in obtaining high MW polymers from aminolysis of 5-membered ring carbonate is commonly observed [45,46,52,79]. The origin of the low MW values associated with PHU is not fully resolved in the literature. One possible reason could be due to the presence of side reactions leading to urea formation and oxazolidinone as well as dehydration products as outlined by Besse et al. [79] Further studies are needed to investigate the origin of this phenomenon and to improve the MW range attainable in PHU synthesis. Recent work by Sardon and coworkers [12] on PHU synthesis at room 
temperature using 8-membered ring carbonate achieved $M_{\mathrm{n}}$ in excess of $40 \mathrm{~kg} / \mathrm{mol}$. Synthesis of segmented PHUs using organic catalyst such as 1,5,7-triazabicyclo[4,4,0] undec-5-ene (TBD) also merits further investigation.

\section{Small-Angle X-Ray Scattering}

The nanophase-separated morphology in TPUs arises from the thermodynamic incompatibility of the hard and soft segments. SAXS is a powerful technique to probe the presence of nanophase-segregated structures, quantify interdomain distances, and evaluate the degree and kinetic of phase separation in TPUs [80-82]. Figure 1 shows the SAXS patterns of CYCDA samples. (See Figure S5a-b for SAXS patterns of HMDA and pXDA samples, respectively.) All PHUs show single interference peaks centered at specific scattering vector locations indicating the presence of nanophase-separated morphology. The interdomain spacing can be calculated using $d=2 \pi / q_{\max }$ where $q_{\max }$ is the magnitude of the scattering vector at maximum intensity. The interdomain spacings are 10-20 nm and increase with increasing hardsegment content. See Table 1 for $d$-spacings of all PHUs produced in this study.

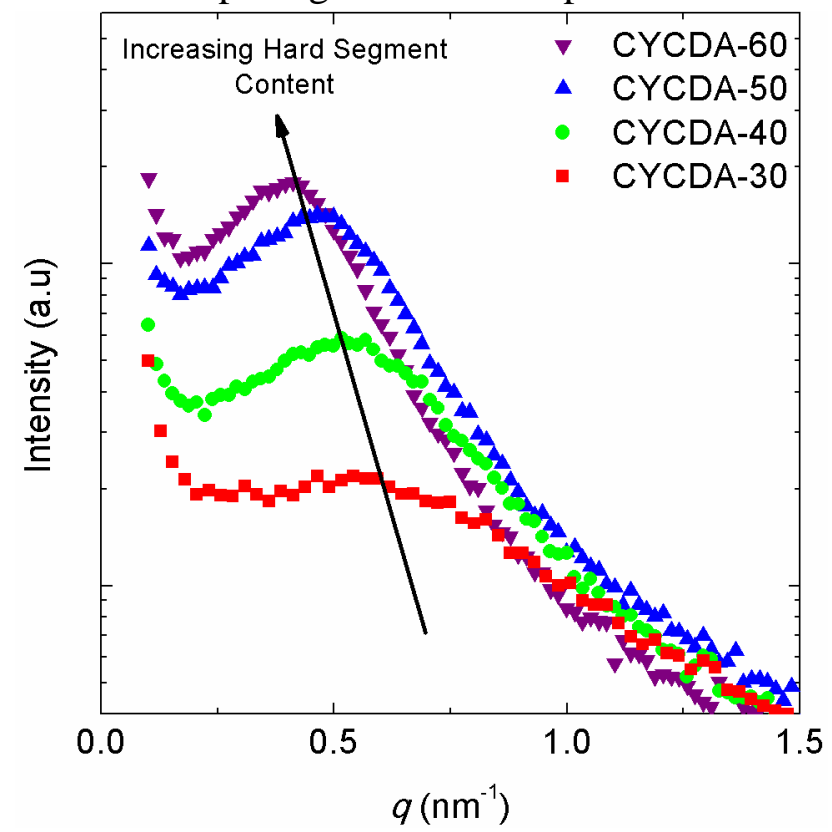

Figure 1. SAXS patterns of PHUs chain extended with (a) 1,3 cyclohexane bis(methyl amine), CYCDA-30 through CYCDA-60.

\section{Tensile Properties}


The nanophase separation in segmented PHUs produces elastomeric material character. Previously, Torkelson and coworkers [54] have shown that thermoplastic PHU elastomers exhibit elastomeric response with some level of hysteresis, qualitatively similar to that observed in TPUs [85]. The tensile properties of the PHUs were analyzed via uniaxial tensile deformation. Figure 2 shows representative tensile stress-strain curves of CYCDA samples. (See Figure S6a-b for representative stress-strain curves of HMDA and pXDA samples.) Samples with 30 to 50 wt $\%$ hard-segment content show elastomeric responses whereas samples with 60 wt\% hardsegment content exhibit yield points, which can be attributed to the change in nanostructure of the materials. As the hard-segment content is increased to $60 \mathrm{wt} \%$, the nanostructure changes from hard segments dispersed in a rubbery matrix to continuous, interconnected hard domains. This yield point can be attributed to the breakage of interconnected, well-percolated hard domains throughout the soft-segment matrix. Sheth et al. [83] also observed yield points in tensile stress-strain responses of segmented polyureas which they attributed to the presence of a well-percolated hard domain, and they supported this claim with evidence from AFM phase imaging. We also note that TPUs and polyurea elastomers may display yield points in their stress-strain curves when tested at a very high strain rate $\left(>1000 \mathrm{~s}^{-1}\right)$. Yi et al. [84] and Sarva et al. [85] performed uniaxial compressive testing at several strain rates on polyurea and polyurethane elastomers and observed yield point at strain rates exceeding $1000 \mathrm{~s}^{-1}$, but Roland et al. [86] did not observe any yield point when performing the test in tension mode. Given that the strain rate used in our experiments is low, yield points observed in samples with $60 \mathrm{wt} \%$ hard-segment content can be attributed to their continuous, well-percolated hard-segment morphology and not to the strain rate used for testing.

Table 2 summarizes the Young's modulus, tensile strength, and elongation at break for all PTMO-based PHUs. The mechanical properties of these PHUs can be tuned by varying the compositions of soft and hard segments. An increase in the hard-segment content leads to increases in Young's modulus and ultimate tensile strength as a direct consequence of increased physical crosslinking sites. Increasing the hard-segment content also leads to a concomitant 
decrease in elongation at break. Young's modulus values ranged from 27 to $200 \mathrm{MPa}$, tensile strength values from 0.3 to $9.7 \mathrm{MPa}$, and elongation at break values from $110 \%$ to greater than 2000\%. The tensile strengths of pXDA samples are generally higher than CYCDA and HMDA

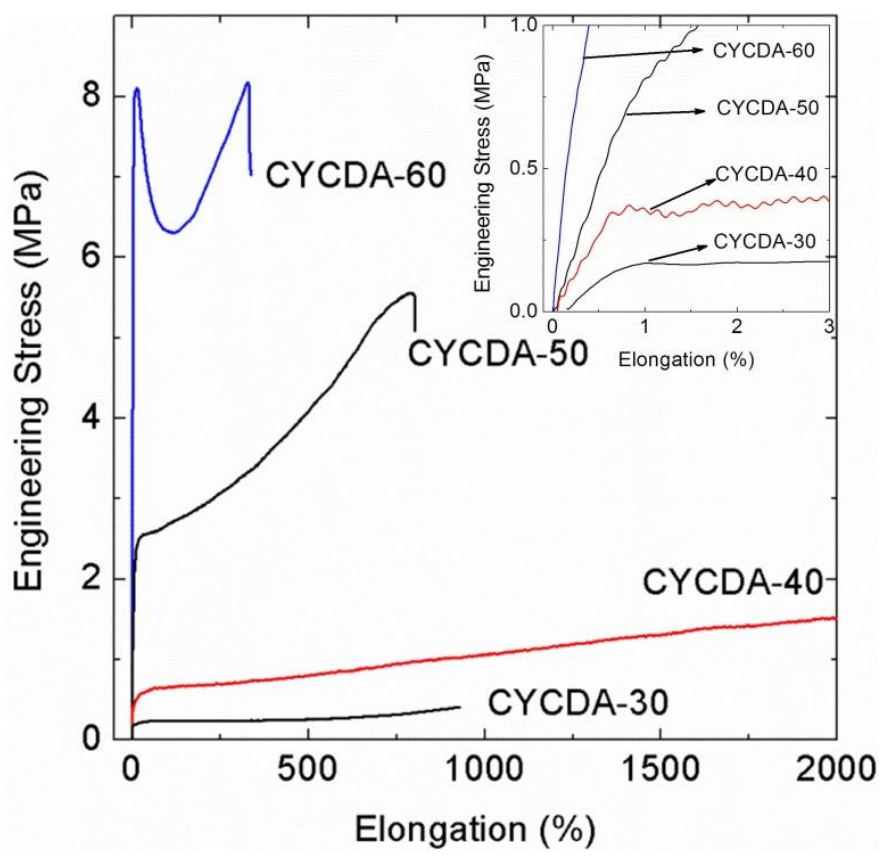

Figure 2. Representative stress-strain curves of PHUs chain extended with 1,3-cyclohexane bis(methyl amine) with hard-segment content of 30 to $60 \mathrm{wt} \%$. Inset: Representative stress-strain curves of CYCDA samples at low elongation.

Table 2 Mechanical properties of PTMO-based PHUs at various hard-segment contents produced with three different chain extenders.*

\begin{tabular}{c|c|c|c}
\hline Sample Name & $\begin{array}{c}\text { Young's Modulus, E } \\
(\mathrm{MPa})\end{array}$ & $\begin{array}{c}\text { Ultimate Tensile } \\
\text { Strength }(\mathrm{MPa})\end{array}$ & $\begin{array}{c}\text { Elongation at } \\
\text { Break } \epsilon_{\mathrm{B}}(\%)\end{array}$ \\
\hline CYCDA-30 & $27 \pm 5$ & $0.40 \pm 0.04$ & $850 \pm 110$ \\
CYCDA-40 & $59 \pm 6$ & $1.4 \pm 0.3$ & No Break \\
CYCDA-50 & $89 \pm 18$ & $4.2 \pm 1.9$ & $670 \pm 160$ \\
CYCDA-60 & $186 \pm 55$ & $6.2 \pm 2.8$ & $220 \pm 100$ \\
\hline HMDA-30 & $27 \pm 5$ & $0.88 \pm 0.27$ & $680 \pm 30$ \\
HMDA-40 & $49 \pm 5$ & $0.50 \pm 0.12$ & No Break \\
HMDA-50 & $51 \pm 6$ & $5.1 \pm 0.8$ & $1100 \pm 50$ \\
HMDA-60 & $110 \pm 46$ & $5.5 \pm 2.4$ & $530 \pm 230$ \\
\hline pXDA-30 & $29 \pm 16$ & $0.3 \pm 0.1$ & No Break \\
pXDA-40 & $74 \pm 17$ & $2.4 \pm 0.5$ & $1400 \pm 160$ \\
pXDA-50 & $121 \pm 14$ & $5.3 \pm 0.5$ & $440 \pm 180$ \\
pXDA-60 & $200 \pm 27$ & $9.7 \pm 1.3$ & $110 \pm 30$ \\
\hline
\end{tabular}

*Values are reported as average of five specimens. Error represents one standard deviation.

samples, likely due to the symmetric and aromatic structure of $p$-xylylene diamine. 
The tensile properties of PHUs produced in this study can be compared to those obtained with conventional TPUs. Schneider and coworkers [87] synthesized a series of TPUs from 2,4TDI, PTMO with $M_{\mathrm{n}}=2000 \mathrm{~g} / \mathrm{mol}$, and 1,4-butanediol as chain extender. They reported tensile strength values ranging from 0.5 to $7.7 \mathrm{MPa}$ and elongation at break values from 1100 to 2100 $\%$. The tensile strength values of PHUs in this study are comparable to those obtained by Schneider and coworkers in TPU [87]. However, they are lower than those obtained by Wilkes and coworkers [58] who studied PTMO-based TPUs synthesized using symmetric paraphenylene diisocyanate ( $p$ PDI); they obtained Young's modulus values ranging from 9 to 31 $\mathrm{MPa}$, tensile strength values from 8 to $20 \mathrm{MPa}$ and elongation at break values from 900 to 1500 $\%$. Their tensile strength values are higher than those we obtained, likely due to the symmetric structure of $p$ PDI and its monodispersity which can lead to a better hard segment association. The DVBDCC molecule employed in our study contains a mixture of meta and para isomers. The urethane linkages in our PHU materials are also placed at least two methylene units away from the aromatic ring as opposed to being directly adjacent to the aromatic ring, as in isocyanate-based TPU. The hydroxyl groups may also cause some steric hindrance to packing or a tight association of the urethane linkages in the hard segment. These hydroxyl groups are also capable of forming hydrogen bonds with the soft segment. This intersegmental hydrogen bonding can lead to some level of phase mixing which can contribute to weaker material strength. However, this slight phase mixing in PTMO-based PHUs results in wide compositional heterogeneity and therefore broad glass transition response that may prove beneficial for application in acoustic or vibrational damping. This aspect will be discussed in the following section.

\section{Dynamic Mechanical Analysis}

The temperature dependences of viscoelastic properties including $E^{\prime}, E^{\prime \prime}$ and $\tan \delta$ of CYCDA-30, HMDA-30 and pXDA-30 samples are shown in Figure 3a-c, respectively. (See Figures S7-S9 for DMA profiles of other PHUs.) Figure 3a-c provides further support for the presence of nanophase separation in these materials as indicated by two thermal transitions: the 
soft-segment $T_{\mathrm{g}}$ as determined from the peak maximum in $E$ " and the flow temperature $\left(T_{\text {flow }}\right)$, indicative of the upper end of hard-segment $T_{\mathrm{g}}$. Table 1 lists the location of the soft-segment $T_{\mathrm{g}}$ and $T_{\text {flow }}$ values for all PHUs. The soft segment $T_{\mathrm{g}} \mathrm{are}-60$ to $-70{ }^{\circ} \mathrm{C}$. The $T_{\text {flow }}$ values range between 51 and $92{ }^{\circ} \mathrm{C}$ for CYCDA samples, from 50 to $90{ }^{\circ} \mathrm{C}$ for pXDA samples, and from 40 to $64{ }^{\circ} \mathrm{C}$ for HMDA samples. The higher $T_{\text {flow }}$ in CYCDA and pXDA samples can be attributed to the more rigid structure of 1,3-cyclohexanebis(methyl amine) and p-xylylene diamine in comparison to the more flexible structure of aliphatic hexamethylene diamine. In all series, $T_{\text {flow }}$ increases with increasing hard-segment content, indicating improved nanophase separation and a more perfected hard domain with increasing hard-segment interdomain spacing. DSC characterization reveals no evidence of crystallinity via a melting peak in the hard segment of our PHUs.

Figure 3a-c also demonstrates that the DMA results for PTMO-based PHUs are qualitatively very different from those observed in PTMO-based TPUs. The $E$ ' in PTMO-based PHUs exhibits a very gradual decrease with respect to temperature above their soft segment $T_{\mathrm{g}}$. The $\tan \delta$-temperature profile also shows high values over a broad temperature range. (See Figures S4-S6 for the DMA profiles of other PHUs which manifest similar behavior.) No rubbery plateau region similar to that obtained in TPUs is present in any of the PTMO-based PHUs. For comparison, we synthesized two TPUs with very similar chemical structures and compositions to CYCDA-30 and HMDA-30 PHUs by using $2000 \mathrm{~g} / \mathrm{mol}$ hydroxyl-terminated PTMO, 2,4-TDI, 1,4-cyclohexanedimethanol and 1,6-hexanediol as chain extenders at $30 \mathrm{wt} \%$ hard-segment content. The DMA results of these TPUs are shown in Figure 4a-b. In contrast to those exhibited by PHUs, the E'-temperature profiles of these TPUs show two distinct drops at two specific locations corresponding to glass transitions of the soft and hard segments. The sharp drop in $E^{\prime}$ near the soft-segment $T_{\mathrm{g}}$ is followed by a relatively temperature-independent rubbery plateau region which extends tens of degree before exhibiting another drop as the sample approaches its hard-segment $T_{\mathrm{g}}$. The corresponding tan $\delta$-temperature profiles of these TPUs 

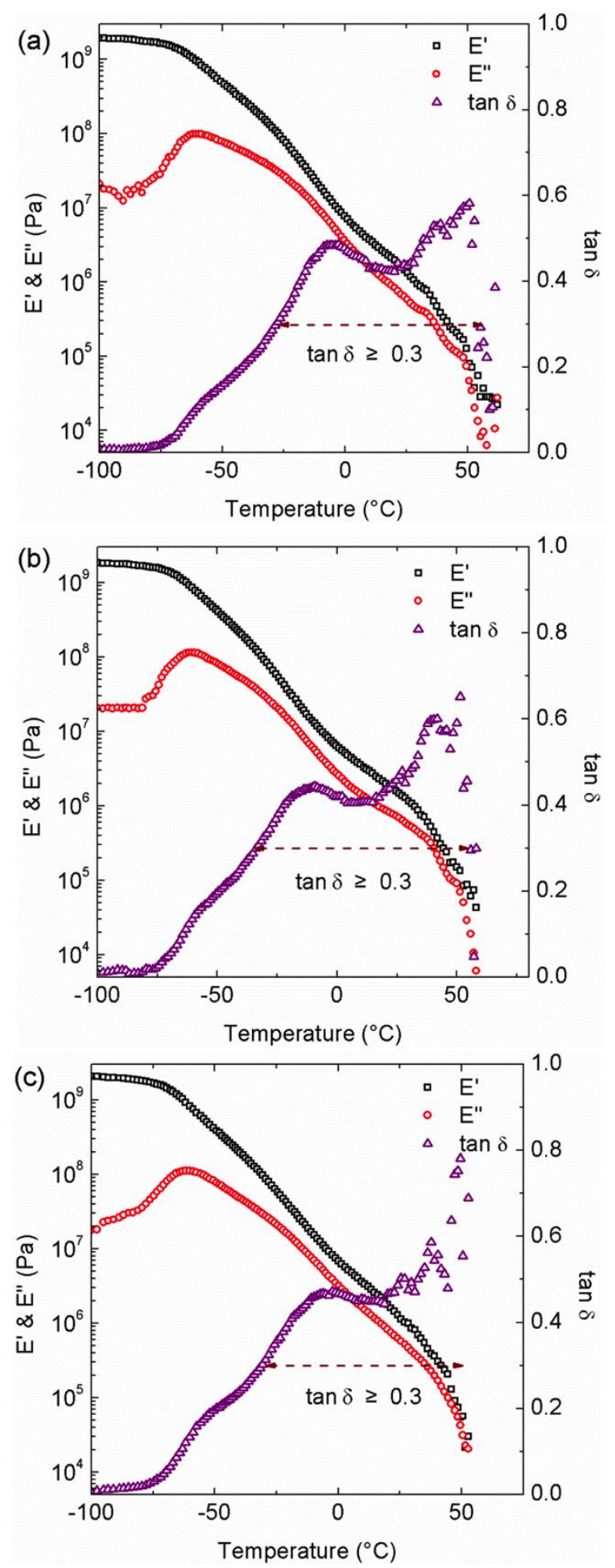

Figure 3. Temperature dependences of tensile storage modulus (E'), loss modulus (E'), and $\tan \delta$ of (a) CYCDA-30, (b) HMDA-30, and (c) pXDA-30 PHUs.

show sharp and narrow peaks at two locations corresponding to the soft- and hard-segment $T_{\mathrm{g}} \mathrm{s}$. The temperature ranges where the $\tan \delta$ continuously exceeds 0.30 in these TPUs are only 
about $10{ }^{\circ} \mathrm{C}$. Similar DMA results have also been reported in PTMO-based TPUs as well as other TPUs employing soft segments such as polyester or polycarbonate [57-69].
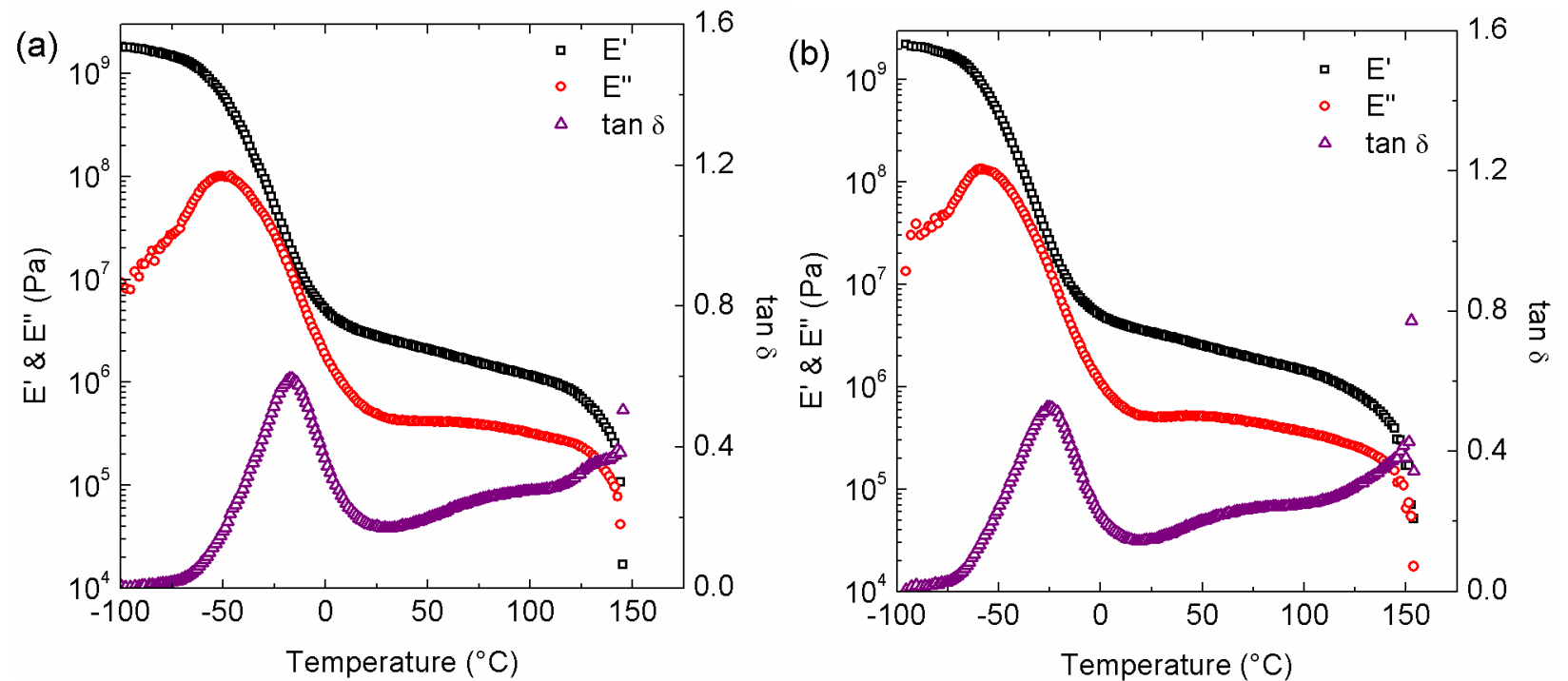

Figure 4. Temperature dependences of tensile storage modulus (E'), loss modulus (E'), and $\tan \delta$ of (a) analogous PU made with PTMO $\left(\mathrm{M}_{\mathrm{n}}=2000 \mathrm{~g} / \mathrm{mol}\right), 2,4$ TDI and 1,4-cyclohexane dimethanol and (b) analogous PU made with PTMO $\left(\mathrm{M}_{\mathrm{n}}=2000 \mathrm{~g} / \mathrm{mol}\right), 2,4 \mathrm{TDI}$ and 1,6-hexanediol at $30 \mathrm{wt} \%$ hard-segment content.

The step change in $E^{\prime}$ and sharp tan $\delta$ peaks observed in TPUs are consequences of very good nanophase separation. Due to the strong hydrogen bonding within hard-segment urethane units, the nanophase separation produces sharp interphases between the hard and soft domains. By contrast, the $E$ ' and tan $\delta$ profile of PTMO-based PHUs (Figure 3a-c) are characteristic of nanophase-separated systems having broad interphases with a wide range of local composition [89]. This is a result of some level of phase mixing due to hydrogen bonding between the hardsegment hydroxyl groups and the soft-segment oxygen atoms. Such profiles are analogous to those seen in gradient copolymer systems known to possess nanophase separation with broad interphase regions and broad ranges of $T_{\mathrm{g}} \mathrm{s}$ [89-95]. Mok et al. [89] compared DMA results of block and gradient copolymers of styrene/n-butyl acrylate and styrene/hydroxystyrene. They observed that block copolymers showed two distinct transitions in $E$ ' with sharp and narrow tan $\delta$ peaks whereas gradient copolymers showed a very gradual decrease in $E^{\prime}$ and high tan $\delta$ values over broad temperature ranges. Their observations concur with results from Karaky et al.[93-95] and theoretical predictions by Hashimoto et al. [96] for tapered block copolymer systems with 
sinusoidal composition variation. Mok et al. [89] and Hashimoto et al. [96] indicated that gradient copolymer systems are good for damping applications. By analogy to gradient copolymer systems, PTMO-based PHUs are advantageous for acoustic and vibration damping applications over a wide range of use temperature.

Sound and vibration damping are important in aircraft, automobiles, and machinery as well as in structural applications for noise reduction and prevention of fatigue failures. In practical damping application, utility over wide ranges of temperature and frequencies is often required. Thus, high $\tan \delta$ values over a broad temperature window are desired good damping performance. Typically, $\tan \delta \geq 0.30$ over a temperature range of $\geq 60{ }^{\circ} \mathrm{C}$ is desired [70-78]. We have used the same criterion to evaluate our PHUs. We use $T_{\text {flow }}$ as the upper limit of service temperature for good damping because characterization of loss factor beyond $T_{\text {flow }}$ is not possible; DMA experiments were performed in tensile mode, and the materials are no longer mechanically robust beyond $T_{\text {flow }}$.

Figure 5a-c shows the temperature dependences of tan $\delta$ for CYCDA, HMDA, and pXDA samples, respectively, at all hard-segment contents. Table 1 summarizes the temperatures and the breadths of regions for which $\tan \delta \geq 0.30$. As shown in Table 2, all PHUs exhibit good damping character spanning at least $\sim 44{ }^{\circ} \mathrm{C}$ with tunable temperature range depending on their compositions. In particular, all pXDA samples exhibit good damping characteristics over temperature range of 64 to $81{ }^{\circ} \mathrm{C}$ whereas CYCDA-30, 40, and 50 exhibit similar damping behavior over temperature ranges of 78,81 , and $57{ }^{\circ} \mathrm{C}$, respectively. Likewise, HMDA-30 and HMDA-40 show good damping characteristics over temperature ranges of 73 and $57{ }^{\circ} \mathrm{C}$. These temperature ranges are tunable depending on hard-segment content and chain extender structure. For example, the good damping range for pXDA-30 PHU spans temperatures from -31 to $50{ }^{\circ} \mathrm{C}$. Increasing the hard-segment content to $40 \mathrm{wt} \%, 50 \mathrm{wt} \%$ and $60 \mathrm{wt} \%$ shifts the good damping regions to 0 to $75^{\circ} \mathrm{C}, 10$ to $80{ }^{\circ} \mathrm{C}$, and 26 to $90{ }^{\circ} \mathrm{C}$, respectively. Similar trends were observed in CYCDA and HMDA samples. Generally, increasing the hard-segment content increases the hard-segment domain size and favors better segregation of the hard domain. The latter outcome 

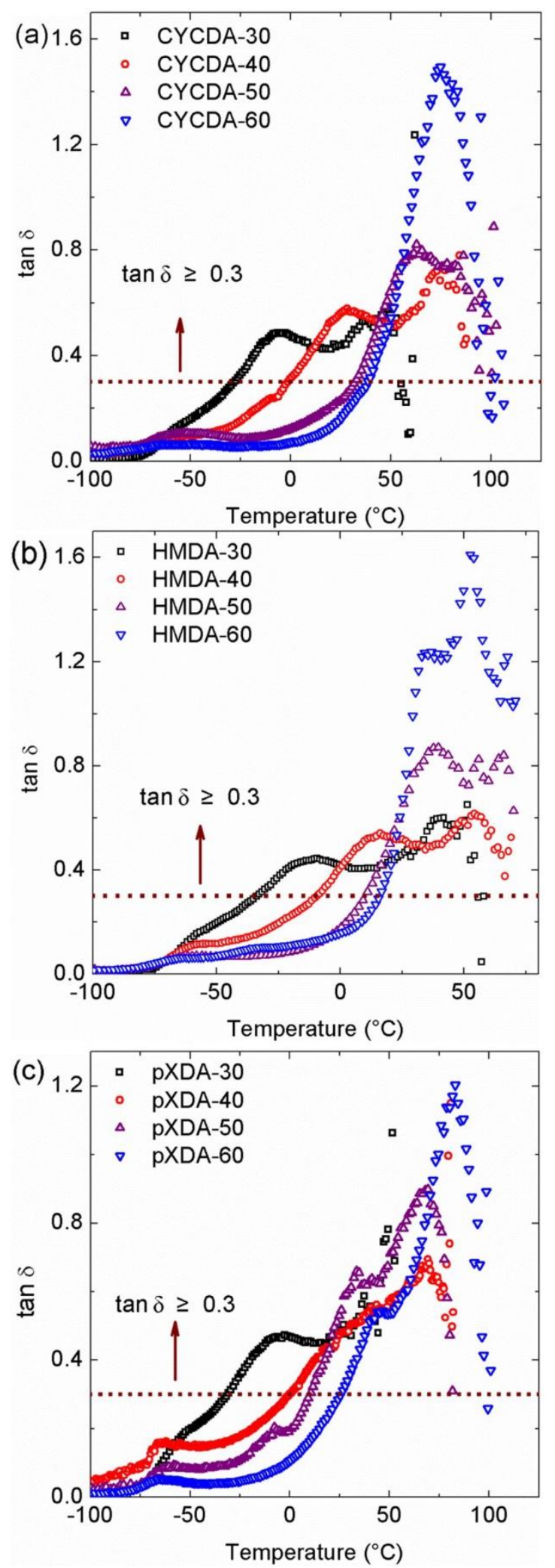

Figure 5. Temperature dependences of $\tan \delta$ of (a) CYCDA-30 through CYCDA-60, (b) HMDA-30 through HMDA-60 and (c) pXDA-30 through pXDA-60. 
results in a shift of the glass transition range to higher temperature. Chain extender structure also impacts the good damping range in these materials. The $T_{\text {flow }}$ values of HMDA samples are lower due to the more flexible structure of the hexamethylene diamine molecule. The breadths of the temperature range with good damping performance are generally similar across samples with similar hard-segment content.

Our results demonstrate that PTMO-based PHUs can be excellent damping materials over broad ranges of use temperature, a function not observed in conventional TPUs. The temperature range for good damping performance can be easily tuned through compositional variation in hard-segment content as well as chain extender structure. We note that polyurethane has previously been investigated for damping applications. To achieve broad-temperature-range damping capability, TPUs are incorporated into IPNs with secondary polymeric components such as epoxy [74], polyester [75], polyacrylate [76,77], polystyrene [78], etc. The IPN structure consists of networks of at least two polymers that are catenated or topologically interlocked by covalent crosslinks resulting in intimate mixing between the two components. This intimate mixing produces microheteregeneous or nanoheteregenous morphology with a broad range of local composition and broad $T_{\mathrm{g}} \mathrm{s}$ resulting in high $\tan \delta$ response useful for acoustic damping application. As demonstrated from our DMA results in Figure 4a-b and by others in a variety of reports [57-69], TPU by itself is unable to serve as a broad-temperature-range damping material due to narrow peaks in $\tan \delta$ response. In contrast, our PTMO-based PHUs show high $\tan \delta$ values over broad temperature ranges without the need to employ an IPN structure.

The extraordinarily broad temperature ranges with $\tan \delta \geq 0.30$ in PTMO-based PHUs are direct consequences of the hard-segment hydroxyl groups forming hydrogen bonds with oxygen atoms in the soft segment. The partial miscibility due to some level of phase mixing results in nanophase-separated systems possessing broad interphases having a wide range of local composition. The PTMO-based PHUs have high $\tan \delta$ values over broad temperature ranges that are easily tunable via material compositions making them useful as broad-temperature-range acoustic and vibration damping materials. These PHU materials are also thermoplastics, and thus 
can be easily processed and molded into a range of shapes or forms to tailor to different applications. Future studies are warranted to consider other applications for which PHUs may possess advantages over conventional polyurethanes, including as adhesives [97].

\section{CONCLUSIONS}

Non-isocyanate-based thermoplastic PHU elastomers were synthesized with cyclic carbonate aminolysis using PTMO as the soft segment and DVBDCC with three different chain extenders as the hard segment. Hard-segment contents were varied from 30 to $60 \mathrm{wt} \%$. FTIR results demonstrate the complete disappearance (within error) of carbonate peaks, indicating successful PHU synthesis at high conversion. SAXS measurements demonstrate that these PHUs possess nanophase-separated morphology with 10-20 nm interdomain spacings as a result of the nanophase separation. PHUs with 30 to $50 \mathrm{wt} \%$ hard-segment content exhibit elastomeric material responses with tunable tensile properties. DMA results reveal that these PTMO-based PHUs possess very different nanophase separation behavior than that exhibited by isocyanatebased TPUs; this difference is a result of some level of phase mixing caused by hydrogen bonding between hard-segment hydroxyl groups and oxygen atoms in the PTMO soft segment. Notable features include a gradual decrease in $E^{\prime}$ with temperature and high $\tan \delta$ values $(\geq 0.30)$ over broad temperature ranges, indicative of a system with a wide range of local composition. Using the criterion of $\tan \delta \geq 0.30$, we demonstrate that these PHUs can serve as effective damping materials over extraordinary temperature ranges as large as $80{ }^{\circ} \mathrm{C}$, a function not present in conventional TPUs. We also demonstrate that the damping temperature ranges are tunable via simple variation of hard-segment content and chain extender structure.

\section{REFERENCES:}

[1] B. Nohra, L. Candy, J.-F. Blanco, C. Guerin, Y. Raoul, Z. Mouloungui, From petrochemical polyurethanes to biobased polyhydroxyurethanes, Macromolecules 46 
(2013) 3771-3792.

[2] G. Oertel, Polyurethane Handbook. 2nd ed.; 1994.

[3] E. Delebecq, J.-P. Pascault, B. Boutevin, F. Ganachaud, On the versatility of urethane/urea bonds: reversibility, blocked isocyanate and non-isocyanate polyurethane, Chem. Rev. 113 (2013) 80-118.

[4] H.-W. Engels, H.-G. Pirkl, R. Albers, R. W. Albach, J. Krause, A. Hoffmann, H. Casselmann, J. Dormish, Polyurethanes: versatile materials and sustainable problem solvers for today’s challenges, Angew. Chem. Int. Ed. 52 (2013) 9422-9441.

[5] Comission Regulation (EC); Official Journal of European Union 2009, N552/2009.

[6] Methylene Diphenyl Isocyanate (MDI) and Related Compounds Action Plan, Toluene Diisocyanate (TDI) Action Plan, U.S Environmental Protection Agency: 2011. EPA news release, www.epa.gov assessed on November 21, 2015.

[7] EPA Proposes Rule to Protect Customers from Harmful Chemicals Found in Homes and Schools, U.S. Environmental Protection Agency: 2015. EPA news release, www.epa.gov assessed on November 21, 2015.

[8] J. Guan, Y. Song, Y. Lin, X. Yin, M. Zuo, Y. Zhao, X. Tao, Q. Zheng, Progress in study of non-isocyanate polyurethane, Ind. Eng. Chem. Res. 50 (2011) 6517-6527.

[9] M. S. Kathalewar, P. B. Joshi, A. S. Sabnis, V. C. Malshe, Non-isocyanate polyurethanes: from chemistry to applications, RSC Adv. 3 (2013) 4110-4129.

[10] H. Blattmann, M. Fleischer, M. Bähr, R. Mülhaupt, Isocyanate- and phosgene-free routes to polyfunctional cyclic carbonates and green polyurethanes by fixation of carbon dioxide, Macromol. Rapid Commun. 35 (2014) 1238-1254.

[11] L. Maissoneuve, O. Lamarzelle, E. Rix, E. Grau, H. Cramail, Isocyanate-free routes to polyurethanes and poly(hydroxyurethanes), Chem. Rev. 115 (2015) 12407-12439.

[12] A. Yuen, A. Bossion, E. Goméz-Bengoa, F. Ruipérez, M. Isik, J. L. Hedrick, D. Mecerreyes, Y. Y. Yang, H. Sardon. Room temperature synthesis of non-isocyanate polyurethane using highly reactive N-substituted 8-membered cyclic carbonates. Polym. 
Chem. 7 (2016) 2105-2111.

[13] V. Besse, F. Camara, C. Voirin, R. Auvergne, S. Caillol, B. Boutevin, Synthesis and applications of unsaturated cyclocarbonates, Polym. Chem. 4 (2013) 4545-4561.

[14] N. Kihara, T. Endo, Synthesis and properties of poly(hydroxyurethanes), J. Polym. Sci., Part A: Polym. Chem. 31 (1993) 2765-2773.

[15] A. Steblyanko, W. Choi, F. Sanda, T. Endo, Addition of five-membered cyclic carbonate with amine and its application to polymer synthesis, J. Polym. Sci., Part A: Polym. Chem. 38 (2000) 2375-2380.

[16] B. Ochiai, S. Inoue, T. Endo, One-pot non-isocyanate synthesis of polyurethanes from bisepoxide, carbon dioxide, and diamine, J. Polym. Sci., Part A: Polym. Chem. 43 (2005) 6613-6618.

[17] H. Tomita, F. Sanda, T. Endo, Structural analysis of polyhydroxyurethane obtained by polyaddition of bifunctional five-membered cyclic carbonate and diamine based on the model reaction, J. Polym. Sci., Part A: Polym. Chem. 38 (2001) 851-859.

[18] H. Tomita, F. Sanda, T. Endo, Reactivity comparison of five- and six-membered cyclic carbonates with amines: basic evaluation for synthesis of poly(hydroxyurethane) J. Polym. Sci., Part A: Polym. Chem. 39 (2001) 162-168.

[19] H. Tomita, F. Sanda, T. Endo, Polyaddition behavior of bis(five- and six-membered cyclic carbonate)s with diamine, J. Polym. Sci., Part A: Polym. Chem. 39 (2001) 860867.

[20] H. Tomita, F. Sanda, T. Endo, Polyaddition of bis(seven-membered cyclic carbonate) with diamines: a novel and efficient synthetic method for polyhydroxyurethanes, J. Polym. Sci., Part A: Polym. Chem. 39 (2001) 4091-4100.

[21] H. Tomita, F. Sanda, T. Endo, Model reaction for the synthesis of polyhydroxyurethanes from cyclic carbonates with amines: substituent effect on the reactivity and selectivity of ring-opening direction in the reaction of five-membered cyclic carbonates with amine $\mathrm{J}$. Polym. Sci., Part A: Polym. Chem. 39 (2001) 3678-3685. 
[22] B. Ochiai, S. Inoue, T. Endo, Salt effect on polyaddition of bifunctional cyclic carbonate and diamine, J. Polym. Sci., Part A: Polym. Chem. 43 (2005) 6282-6286.

[23] B. Ochiai, Y. Satoh, T. Endo, Nucleophilic polyaddition in water based on chemoselective reaction of cyclic carbonate with amine, Green Chem. 7 (2005) 765-767.

[24] M.-R. Kim, H.-S. Kim, C.-S. Ha, D.-W. Park, J.-K. Lee, Syntheses and thermal properties of poly(hydroxy)urethanes by polyaddition reaction of bis(cyclic carbonate) and diamine, J. Appl. Polym. Sci. 81 (2001) 2735-2743.

[25] O. L. Figovsky, L. D. Shapovalov, Features of reaction amino-cyclocarbonate for production of new type nonisocyanate polyurethane coatings, Macromol. Symp. 187 (2002) 325-332.

[26] O. Birukov, O. Figovsky, A. Leykin, R. Potashnikov, L. Shapovalov, Method of producing hybrid polyhydroxyurethane network on a base of carbonated-epoxidized unsaturated fatty acid triglycerides. U.S. Patent 20120208967, Aug 16, 2012.

[27] J. L. J. Van Velthoven, L. Gootjes, D. S. van Es, B. A. J. Noordover, J. Meuldijk, Poly(hydroxyl urethane)s based on renewable diglycerol dicarbonate, Eur Polym. J. 70 (2015) 125-135.

[28] C. Duval, N. Kébir, R. Jauseau, F. Burel, Organocatalytic synthesis of novel renewable non-isocyanate polyhydroxyurethanes, J Polym. Sci., Part A: Polym. Chem. 54 (2015) 758-764.

[29] M. Tryznowski, A. Świderska, Z. Żolek-Tryznowska, T. Gołofit, P. G. Parzuchowski, Facile route to multigram synthesis of environmentally friendly non-isocyanate polyurethanes, Polymer, 80 (2015) 228-236.

[30] R. Lambeth, T. J. Henderson, Organocatalytic synthesis of (poly)hydroxyurethanes from cyclic carbonates and amines, Polymer 54 (2013) 5568-5573.

[31] V. M. Lombardo, E. A. Dhuslt, E. K. Leitsch, N. Wilmot, W. H. Heath, A. P. Gies, M. D. Miller, J. M. Torkelson, K. A. Scheidt, Cooperative catalysis of cyclic carbonate ring opening: application towards non-isocyanate polyurethane materials, Eur. J. Org. Chem. 
13 (2015) 2791-2795.

[32] M. Blain, L. Jean-Gérard, R. Auvergne, D. Benazet, S. Caillol, B. Andrioletti, Rational investigations in the ring opening of cyclic carbonates by amines, Green Chem. 16 (2014) 4286-4291.

[33] M. Bähr, R. Mülhaupt, Cyclic limonene dicarbonate as a new monomer for nonisocyanate oligo- and polyurethanes (NIPU) based upon terpenes, Green Chem. 14 (2012) 483-489.

[34] B. Tamami, S. Sohn, G. L. Wilkes, Incorporation of carbon dioxide into soybean oil and subsequent preparation and studies of nonisocyanate polyurethane networks, J. Appl. Polym. Sci. 92 (2004) 883-891.

[35] I. Javni, D. P. Hong, Z. S. Petrović, Soy-based polyurethanes by nonisocyanate route, J. Appl. Polym. Sci. 108 (2008) 3867-3875.

[36] I. Javni, D. P. Hong, Z. S. Petrović, Polyurethanes from soybean oil, aromatic, and cycloaliphatic diamines by nonisocyanate route, J. Appl. Polym. Sci. 128 (2013) 566571.

[37] M. Bähr, A. Bitto, R. Mülhaupt, Cyclic limonene dicarbonate as a new monomer for nonisocyanate oligo- and polyurethanes (NIPU) based upon terpenes, Green Chem. 14 (2012) 1447-1454.

[38] M. Fleischer, H. Blattmann, R. Mülhaupt, Glycerol-, pentaerythritol- and trimethylolpropane-based polyurethanes and their cellulose carbonate composites prepared via the non-isocyanate route with catalytic carbon dioxide fixation, Green Chem. 15 (2013) 934-942.

[39] V. Besse, R. Auvergne, S. Carlotti, G. Boutevin, B. Otazaghine, S. Caillol, J.-P. Pascault, B. Boutevin, Synthesis of isoorbide based polyurethanes: An isocyanate free method, React. Funct. Polym. 73 (2013) 588-594.

[40] M. Kathalewar, A. Sabnis, D. D’Mello, Isocyanate free polyurethanes from new CNSL based bis-cyclic carbonate and its application in coatings, Eur. Polym. J. 57 (2014) 99- 
108

[41] A. Lee, Y. Deng, Green polyurethane from lignin and soybean oil through non-isocyanate reactions, Eur. Polym. J. 63 (2015) 67-73.

[42] D. J. Fortman, J. P. Brutman, C. J. Cramer, M. A. Hillmyer, W. R. Dichtel, Mechanically activated, catalyst-free polyhydroxyurethane vitrimers, J. Am. Chem. Soc. 137 (2015) 14019-14022.

[43] H. Matsukizono, T. Endo, Synthesis of polyhydroxyurethanes from di(trimethylolpropane) and their application to quaternary ammonium chloridefunctionalized films, RSC Adv. 5 (2015) 71360-71369.

[44] A. Cornille, S. Dworakowska, D. Bogdal, B. Boutevin, S. Caillol, Syntheses of epoxyurethane polymers from isocyanate free oligo-polyhydroxyurethanes, Eur. Polym. J. 66 (2015) 129-138.

[45] S. Benyahya, M. Desroches, R. Auvergne, S. Carlotti, S. Caillol, B. Boutevin, Synthesis of glycerin carbonate-based intermediates using thiol-ene chemistry and isocyanate free polyhydroxyurethanes therefrom, Polym. Chem. 2 (2011) 2661-2667.

[46] S. Benyahya, J.-P. Habas, R. Auvergne, V. Lapinte, S. Caillol, Structure-property relationships in polyhydroxyurethanes produced from terphthaloyl dicyclocarbonate with various polyamines, Polym. Int. 61 (2012) 1666-1674.

[47] L. Maisonneuve, A. S. More, S. Foltran, C. Alfos, F. Robert, Y. Landais, T. Tassaing, E. Grau, H. Cramail, Novel green fatty acid-based bis-cyclic carbonates for the synthesis of isocyanate-free poly(hydroxyurethane amide)s, RSC Adv. 4 (2014) 25795-25803.

[48] C. N. Tang, H. B. Nulwala, K. Damodaran, P. Kaur, D. R. Luebke, Tunable poly(hydroxyl urethane) from $\mathrm{CO}_{2}$-based intermediates using thiol-ene chemistry, J. Polym. Sci. Part A: Polym. Sci. 49 (2011) 2024-2032.

[49] T. Lebarbé, A. S. More, P. S. Sane, E. Grau, C. Alfos, H. Cramail, Bio-based aliphatic polyurethanes through ADMET polymerization in bulk and green solvent, Macromol. Rapid Commun. 35 (2014) 479-483. 
[50] X. Sheng, G. Ren, Y. Qin, X. Chen, X. Wang, F. Wang, Quantitative synthesis of bis(cyclic carbonate)s by iron catalyst for non-isocyanate polyurethane synthesis, Green Chem. 17 (2015) 373-379.

[51] L. Maisonneuve, A.-L. Wirotius, C. Alfos, E. Grau, H. Cramail, Fatty acid-based (bis) 6membered cyclic carbonates as efficient isocyanate free poly(hydroxyurethane) precursors. Polym. Chem. 5 (2014) 6142-6147.

[52] O. Lamarzelle, P.-L. Durand, A.-L. Wirotius, G. Chollet, E. Grau, H. Cramail. Activated lipidic cyclic carbonates for non-isocyanate polyurethane synthesis. Polym. Chem. 7 (2016) 1439-1451.

[53] J. Nanclares, Z. S. Petrović, I. Javni, M. Ionescu, F. Jaramillo, Segmented polyurethane elastomers by nonisocyanate route, J. Appl. Polym. Sci. 132 (2015) 42492.

[54] E. K. Leitsch, G. Beniah, K. Liu, T. Lan, W. H. Heath, K. A. Scheidt, J. M. Torkelson, Nonisocyanate thermoplastic polyhydroxyurethane elastomers via cyclic carbonate aminolysis: critical role of hydroxyl groups in controlling nanophase separation, ACS Macro Lett. 5 (2016) 424-429.

[55] Hepburn, C., Polyurethane Elastomers. (Chapter 3 Property Structure Relationships) 2nd ed.; Springer Link: 1992.

[56] Holden, G.; Kricheldorf, H. R.; Quirk, R. P., Thermoplastic Elastomers. (Chapter 2: Thermoplastic Polyurethane Elastomers) 3rd ed.; Hanser: 2004.

[57] L. T. J. Korley, B. D. Pate, E. L. Thomas, P. T. Hammond, Effect of the degree of soft and hard segment ordering on the morphology and mechanical behavior of semicrystalline segmented polyurethanes, Polymer 47 (2006) 3073-3082.

[58] D. B. Klinedinst, I. Yilgör, E. Yilgör, M. Zhang, G. L. Wilkes, The effect of varying soft and hard segment length on the structure-property relationships of segmented polyurethanes based on a linear symmetric diisocyanate, 1,4-butanediol and PTMO soft segments, Polymer 53 (2012) 5358-5366.

[59] S. Das, D. F. Cox, G. L. Wilkes, D. B. Klinedinst, I. Yilgör, E. Yilgör, F. L. Beyer, Effect 
of symmetry and H-bond strength of hard segments on the structure-property relationships of segmented, nonchain extended polyurethanes and polyureas, $\mathrm{J}$. Macromol. Sci., Part B: Phys. 46 (2007) 853-875.

[60] M. J. O’Sickey, B. D. Lawrey, G. L. Wilkes, Structure-property relationships of poly(urethane urea)s with ultra-low monol content poly(propylene glycol) soft segments. I. Influence of soft segment molecular weight and hard segment content, J. Appl. Polym. Sci. 84 (2002) 229-243.

[61] M. J. O’Sickey, B. D. Lawrey, G. L. Wilkes, Structure-property relationships of poly(urethane-urea)s with ultra-low monol content poly(propylene glycol) soft segments. Part II. Influence of low molecular weight polyol components, Polymer 43 (2002) 73997408.

[62] M. J. O’Sickey, B. D. Lawrey, G. L. Wilkes, Structure-property relationships of poly(urethane-urea)s with ultralow monol content poly(propylene glycol) soft segments. III. Influence of mixed soft segments of ultralow monol poly(propylene glycol), poly(tetramethylene ether glycol), and tri(propylene glycol), J. Appl. Polym. Sci. 89 (2003) 3520-3529.

[63] I. Yilgor, E. Yilgor, G. L. Wilkes, Critical parameters in designing segmented polyurethanes and their effect on morphology and properties: A comprehensive review, Polymer 58 (2015) A1-A36.

[64] C. G. Seefried, J. V. Koleske, F. E. Critchifield, Thermoplastic urethane elastomers. I. Effects of soft-segment variations, J. Appl. Polym. Sci. 19 (1975) 2493-2502.

[65] C. G. Seefried, J. V. Koleske, F. E. Critchfield, Thermoplastic urethane elastomers. II. Effects of variations in hard-segment concentration, J. Appl. Polym. Sci. 19 (1975) 25032513.

[66] C. G. Seefried, J. V. Koleske, F. E. Critchfield, Thermoplastic urethane elastomers. III. Effects of variations in isocyanate structure, J. Appl. Polym. Sci. 19 (1975) 3185-3191.

[67] C. G. Seefried, J. V. Koleske, F. E. Critchfield, Thermoplastic urethane elastomers IV. 
Effects of cycloaliphatic chain extender on dynamic mechanical properties, Polym. Eng. Sci. 15 (1975) 646-650.

[68] K. Kojio, M. Furukawa, S. Motokucho, M. Shimada, M. Sakai, Structure-mechanical property relationships for poly(carbonate urethane) elastomers with novel soft segments, Macromolecules 42 (2009) 8322-8327.

[69] A. Eceiza, M. D. Martin, K. de la Caba, G. Kortaberria, N. Gabilondo, M. A. Corcuera, I. Mondragon, Thermoplastic polyurethane elastomers based on polycarbonate diols with different soft segment molecular weight and chemical structure: mechanical and thermal properties, Polym. Eng. Sci. 48 (2008) 297-306.

[70] Sophiea, D.; Klempner, D.; Sendijarevic, V.; Suthar, B.; Frisch, K. C., "Interpenetrating Polymer Networks as Energy-Absorbing Materials" in Interpenetrating Polymer Networks, Advances in Chemistry Series 239, ACS Washington, DC 1994. Edited by Klempner, D.; Sperling, L. H.; Utracki, L. A.

[71] V. Huelck, D. A. Thomas, L. H. Sperling, Interpenetrating polymer networks of poly(ethyl acrylate) and poly(styrene-co-methyl methacrylate). I. Morphology via electron microscopy, Macromolecules 5 (1972) 340-347.

[72] V. Huelck, D. A. Thomas, L. H. Sperling, Interpenetrating polymer networks of poly(ethyl acrylate) and poly(styrene-co-methyl methacrylate). II. Physical and mechanical behavior, Macromolecules 5 (1972) 348-353.

[73] R. Hu, V. L. Dimonie, M. S. El-Aasser, R. A. Pearson, A. Hiltner, S. G. Mylonakis, L. H. Sperling, Multicomponent latex IPN materials: 2. Damping and mechanical behavior, J. Polym. Sci., Part B: Polym. Phys. 35 (1997), 1501-1514.

[74] Y. C. Chern, S. M. Tseng, K. H. Hsieh, Damping properties of interpenetrating polymer networks of polyurethane-modified epoxy and polyurethanes, J. Appl. Polym. Sci. 74 (1999) 328-335.

[75] C.-L. Qin, W.-M. Cai, J. Cai, D.-Y. Tang, J.-S. Zhang, M. Qin, Damping properties and morphology of polyurethane/vinyl ester resin interpenetrating polymer network, Mater. 
Chem. Phys. 85 (2004) 402-409.

[76] Q. Chen, H. Ge, D. Chen, X. He, X. Yu, Investigation on damping behavior and morphology of polyurethane/polymethacrylates and polyacrylates interpenetrating polymer networks, J. Appl. Polym. Sci. 54 (1994) 1191-1197.

[77] X. Yu, G. Gao, J. Wang, F. Li, X. Tang, Damping materials based on polyurethane/polyacrylate IPNs: dynamic mechanical spectroscopy, mechanical properties and multiphase morphology, Polym. Int. 48 (1999) 805-810.

[78] D. J. Hourston, F.-U. Schäfer, Poly(ether urethane)/poly(ethyl methacrylate) IPNs with high damping characteristics: the influence of the crosslink density in both networks, Polym. Adv. Tech. 62 (1996) 273-280.

[79] V. Besse, F. Camara, F. Méchin, E. Fleury, S. Caillol, J.-P. Pascault, B. Boutevin, How to explain low molar masses in PolyHydroxyUrethanes (PHUs), Eur. Polym. J. 71 (2015) 111 .

[80] G. L. Wilkes, S. Abouzahr, SAXS studies of segmented polyether poly(urethaneurea) elastomers, Macromolecules 14 (1981) 456-458.

[81] Y. Li, T. Gao, B. Chu, Synchrotron SAXS studies of the phase-separation kinetics in a segmented polyurethane, Macromolecules 25 (1992) 1737-1742.

[82] Y. Li, T. Gao, J. Liu, K. L. Liu, C. R. Desper, B. Chu, Multiphase structure of a segmented polyurethane: effects of temperature and annealing, Macromolecules 25 (1992) 7365-7372.

[83] J. P. Sheth, D. B. Klinedinst, G. L. Wilkes, I. Yilgor, E. Yilgor, Role of chain symmetry and hydrogen bonding in segmented copolymers with monodisperse hard segments, Polymer 46 (2005) 7317-7322.

[84] J. Yi, M. C. Boyce, G. F. Lee, E. Balizer, Large deformation rate-dependent stress-strain behavior of polyurea and polyurethanes, Polymer 47 (2006) 319-329.

[85] S. S. Sarva, S. Deschanel, M. C. Boyce, W. Chen, Stress-strain behavior of a polyurea and a polyurethane from low to high strain rates, Polymer 48 (2007) 2208-2213. 
[86] C. M. Roland, J. N. Twigg, Y. Vu, P. H. Mott, High strain rate mechanical behavior of polyurea, Polymer 48 (2007) 574-578.

[87] B. Fu, W. J. MacKnight, N. S. Schneider, Structure-property relationships of segmented polyurethanes containing monodisperse 2,4-toluene diisocyanate/butanediol hard segments, Rubber. Chem. Tech. 59 (1986) 896-911.

[88] M. Furukawa, Y. Mitsui, T. Fukumaru, K. Kojio, Microphase-separated structure and mechanical properties of novel polyurethane elastomers prepared with ether based diisocyanate, Polymer 46 (2005) 10817-10822.

[89] M. M. Mok, J. Kim, J. M. Torkelson, Gradient copolymers with broad glass transition temperature regions: design of purely interphase compositions for damping applications, J. Polym. Sci., Part B: Polym. Phys. 46 (2008) 48-58.

[90] M. M. Mok, J. Kim, C. L. H. Wong, S. R. Marrou, D. J. Woo, C. M. Dettmer, S. T. Nguyen, C. J. Ellison, K. R. Shull, J. M. Torkelson, Glass transition breadths and composition profiles of weakly, moderately, and strongly segregating gradient copolymers: experimental results and calculations from self-consistent mean-field theory, Macromolecules 42 (2009) 7863-7876.

[91] M. M. Mok, J. Kim, S. R. Marrou, J. M. Torkelson, Ellipsometry measurements of glass transition breadths in bulk films of random, block, and gradient copolymers, Eur. Phys. J. E. 31 (2010) 239-252.

[92] J. Kim, M. M. Mok, R. W. Sandoval, D. J. Woo, J. M. Torkelson, Uniquely broad glass transition temperatures of gradient copolymers relative to random and block copolymers containing repulsive comonomers, Macromolecules 39 (2006) 6152-6160.

[93] K. Karaky, E. Péré, C. Pouchan, J. Desbrières, C. Dérail, L. Billon, Effect of the synthetic methodology on molecular architecture: from statistical to gradient copolymers, Soft Matter 2 (2006) 770-778.

[94] K. Karaky, L. Billon, C. Pouchan, J. Desbrières, Amphiphilic gradient copolymers shape composition influence on the surface/bulk properties, Macromolecules 40 (2007) 458- 
464.

[95] K. Karaky, C. Derail, G. Reiter, L. Billon, Tuning the surface/bulk properties by the control of the amiphiphilic profile in gradient copolymer, Macromol. Symp. 267 (2008) $31-40$.

[96] T. Hashimoto, Y. Tsukahara, K. Tachi, H. Kawai, Structure and properties of tapered block polymers. 4. "domain-boundary mixing" and "mixing-in-domain" effects on microdomain morphology and linear dynamic mechanical response, Macromolecules 16 (1983) 648-657.

[97] E. K. Leitsch, W. H. Heath, J. M. Torkelson, Polyurethane/polyhydroxyurethane hybrid polymers and their applications as adhesive bonding agents, Int. J. Adhes. Adhes. 64 (2016) 1-8.

\section{ACKNOWLEDGEMENTS}

This research was supported by the University Partnership Initiative between Northwestern University and The Dow Chemical Company. This work made use of central facilities supported by the MRSEC program of the National Science Foundation (DMR-1121262) at the Northwestern University Materials Research Science and Engineering Center as well as facilities supported by Northwestern University at the Integrated Molecular Structure Education and Research Center. We also thank Dr. Junho Jeon and Ms. Alicia Scott from The Dow Chemical Company, Analytical Sciences lab, Freeport, TX for their help with molecular weight characterization. 